\title{
Faktor-faktor yang mempengaruhi produksi kopi arabika
}

\author{
Hugolinus J. B. Pangkur ${ }^{1 *}$, Marthen R. Pellokila ${ }^{1}$, I Nyoman Sirma ${ }^{1}$ \\ ${ }^{1}$ Program Studi Agribisnis, Fakultas Pertanian, Universitas Nusa Cendana, Kupang, Indonesia \\ *E-mail: joepangkur01@gmail.com
}

\begin{abstract}
Coffee has become the foundation of the economy of the community, including in Manggarai, East Nusa Tenggara. In running their farms, farmers find a problem, namely low production. The purpose of this study was to analyze the relationship and influence of Arabica coffee production factors. The sample in this study amounted to 83 farmers. The research data uses primary and secondary data. The data analysis method uses correlation analysis (Bivariate Correlation) and the Cobb Douglas production function model. The results showed that the factors that have a relationship with Arabica coffee farming production are fertilizer, seeds, labor, land area, and household size. In contrast, factors that have no relationship with production are education level, farming experience, and farmer's age. The factors that affect the production of Arabica coffee farming are seeds, land area, and household size. In contrast, factors that did not affect production were fertilizer, education level, labor, farming experience, and age.
\end{abstract}

Keywords: Arabica coffee, production, Bivariate Correlation, Cobb Douglas

Abstrak. Kopi telah menjadi tumpuan perekonomian keluarga masyarakat termasuk di Manggarai, Nusa Tengga Timur. Dalam menjalankan usahataninya, petani menemukan masalah yaitu produksi yang masih rendah. Tujuan penelitian ini adalah menganalisis hubungan dan pengaruh faktor-faktor produksi kopi arabika. Sampel dalam penelitian ini berjumlah 83 petani. Data penelitian menggunakan data primer dan sekunder. Metode analisis data menggunakan analisis korelasi (Bivariate Correlation) dan model fungsi produksi Cobb Douglas. Hasil penelitian menunjukan bahwa faktor yang memiliki hubungan dengan produksi usahatani kopi arabika adalah pupuk, bibit, tenaga kerja, luas lahan dan tanggungan keluarga, sedangkan faktor yang tidak memiliki hubungan dengan produksi adalah tingkat pendidikan, pengalaman usahatani dan umur petani. Faktor yang mempengaruhi produksi usahatani kopi arabika adalah bibit, luas lahan dan tanggungan keluarga, sedangkan faktor yang tidak berpengaruh terhadap produksi adalah pupuk, tingkat pendidikan, tenaga kerja, pengalaman usahatani dan umur.

Kata Kunci: kopi arabika, produksi, Bivariate Correlation, Cobb Douglas

\section{PENDAHULUAN}

Indonesia merupakan salah satu negara agraris terbesar. Hal ini dapat dilihat dari banyaknya penduduk Indonesia yang bekerja dibidang pertanian. Pertanian memegang peran penting dalam pembangunan perekonomian di Indonesia. Sehingga sektor pertanian merupakan sektor yang sangat penting keberadaannya di Indonesia. Oleh karena itu, pembangunan disektor pertanian menjadi sangat penting dalam peningkatan perekonomian Indonesia. Menurut Muhyidin (2010), pembangunan merupakan suatu proses perubahan menyeluruh yang meliputi usaha penyelarasan keseluruhan sistem ekonomi yang terdapat dalam suatu masyarakat sehingga membawa kemajuan dalam arti meningkatkan taraf hidup masyarakat yang bersangkutan. Pembangunan pertanian perlu terus diperhatikan, dikembangkan dan diawasi oleh pemerintah agar terciptanya pertanian yang maju dan tangguh.

Subsektor perkebunan merupakan salah satu sumber devisa sektor pertanian. Tanaman kopi termasuk subsektor perkebunan dalam sektor pertanian yang merupakan salah satu komoditas unggulan di Indonesia. Pada tahun 2017 luas lahan tanaman kopi yakni 1.227.787 ha dan produksinya 
sebesar 637.539 ton (Statistik Perkebunan Indonesia, 2017). Tanaman kopi di Indonesia ada berbagai jenis, namun yang paling banyak di ekspor keluar negeri adalah jenis kopi robusta dan kopi arabika.

Kabupaten Manggarai Timur merupakan salah satu kabupaten di Provinsi NTT yang memiliki produktivitas kopi tinggi. Produktivitas tanaman kopi di Kabupaten Manggarai Timur dalam lima tahun terakhir berfluktuasi. Pada tahun 2011-2012 terjadi penurunan produktivitas yakni dari 0,20 ton/ha menjadi 0,16 ton/ha sedangkan tahun 2013-2014 mengalami peningkatan cukup besar yakni dari 0,23 ton/ha menjadi 0,35 ton/ha. Di tahun 2015 terjadi peningkatan lagi yakni sebesar 0,40 ton/ha. Kopi yang banyak diproduksi di kabupaten ini adalah kopi jenis robusta dan arabika.

Data dari BPS Kabupaten Manggarai Timur (2017), menunjukan bahwa produksi kopi arabika di Kecamatan Poco Ranaka Timur adalah 27 ton dengan luas lahan 355,76 ha atau 75,8 kg/ha. Desa Colol merupakan salah satu desa yang membudidayakan tanaman kopi. Pada tahun 2018 lahan kopi arabika di Desa Colol yaitu 392 ha dengan produksi 115,2 ton (Rencana Kerja Tahunan Penyuluhan Pertanian, 2018). Pada tahun 2015 kopi Colol ini sudah diakui cita rasa dan kualitasnya dalam Festival Kopi Indonesia di Kabupaten Banyuwangi, Jawa Timur (Chai D, 2017). Masyarakat desa Colol menjadikan kopi sebagai tumpuan pendapatan ekonomi keluarga. Dalam menjalankan usahataninya, petani kopi di Desa Colol masih menemukan berbagai macam permasalahan salah satunya produksi yang masih rendah. Usaha peningkatan produksi ini, dapat dilakukan dengan mengetahui faktor apa saja yang mempengaruhi produksi dan meningkatkan efisiensi penggunaan dari setiap faktor tersebut.

Tujuan penelitian ini adalah untuk menganalisis faktor-faktor yang memiliki hubungan dengan produksi dan faktor-faktor yang mempengaruhi produksi kopi arabika.

\section{METODE}

Penelitian ini telah dilakukan Kecamatan Poco Ranaka Timur Kabupaten Manggarai Timur pada bulan Juli-Agustus 2019. Penentuan tempat penelitian ini dilakukan secara sengaja (Purposive) dengan pertimbangan 1) kualitas dan cita rasa kopi arabika sudah diakui; 2) produksi lebih besar dari desa lain. Populasi dalam penelitian ini adalah petani kopi arabika yang sedang menjalankan usahatani kopi yaitu 500 petani. Penentuan sampel penelitian ditentukan melalui metode simple random sampling (secara acak sederhana), dengan menggunakan rumus Slovin sehingga didapat 83 petani responden. Data yang digunakan dalam penelitian ini adalah data primer dan data sekunder. Data Primer merupakan data yang diperoleh dari petani sampel dengan metode wawancara (interview). Data Sekunder merupakan data yang diperoleh dari studi pustaka (dengan menelaah bukubuku/perpustakaan) pada instansi terkai.

\subsection{Konsep Pengamatan dan Pengukuran}

Variabel yang digunakan dalam penelitian ini adalah 1) jumlah produksi kopi arabika, satuan kilogram (kg); 2) jumlah pupuk, satuan kilogram (Kg); 3) jumlah bibit, satuan (pohon); 4) jumlah tenaga kerja, satuan Hari Kerja Pria (HKP); 5) luas lahan, satuan are; 6) umur adalah satuan tahun; 7) tanggungan keluarga, satuan orang; 8) pengalaman usahatani, satuan tahun, 9) tingkat pendidikan formal, satuan tahun.

\subsection{Metode Analisis Data}

Untuk mengetahui faktor-faktor yang memiliki hubungan dengan produksi usahatani kopi Kabupaten Manggarai Timur maka di gunakan analisis korelasi sederhana (Bivariate Correlation). Analisis korelasi sederhana dapat dilakukan dengan cara: 1) dilihat dari nilai kofisien korelasi, jika korelasi 0 maka artinya tidak ada korelasi sama sekali, sementara jika korelasi 1 berarti ada korelasi sempurna. Selain itu nilai koefisien korelasi mendekati 1 atau -1 maka hubungan antara dua variabel adalah semakin kuat. 2) dilihat dari tanda korelasi, tanda negatif (-) menunjukkan adanya arah yang berlawanan, sedangkan tanda positif $(+)$ menunjukkan arah yang sama atau korelasi searah.

Untuk mengetahui pengaruh faktor-faktor produksi terhadap produksi usahatani kopi arabika Kabupaten Manggarai Timur maka digunakan metode model fungsi produksi Cobb Douglas. Secara metematik:

$$
\begin{aligned}
\mathrm{Y}= & \beta 0 X 1^{\beta 1} X 2^{\beta 2} X 3^{\beta 3} X 4^{\beta 4} X 5^{\beta 5} X 6^{\beta 6} \\
& X 7^{\beta 7} X 8^{\beta 8}
\end{aligned}
$$


Untuk menggunakan model persamaan diatas maka persamaan tersebut diubah menjadi bentuk linear berganda dengan cara melogaritmakan sebagai berikut:

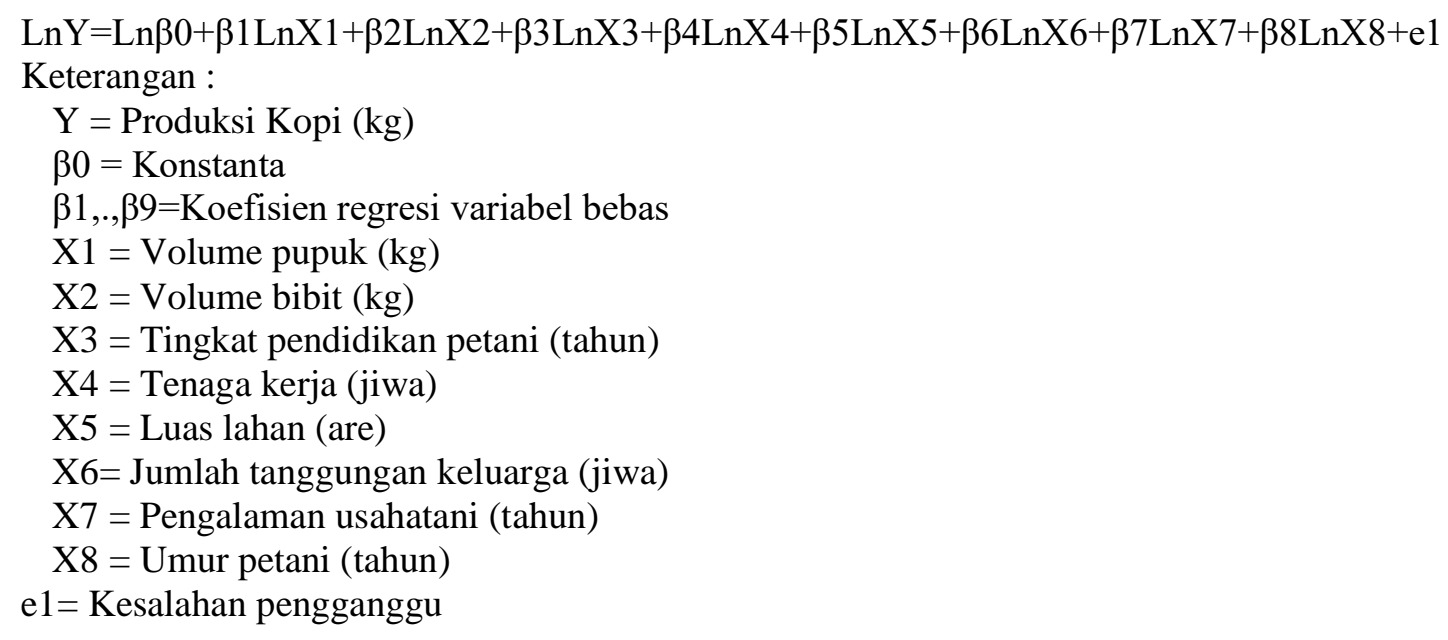

\subsection{Pengukuran Ketepatan Model $\mathbf{R}^{2}$}

Menurut Gujarati (1978) dalam Arwinni (2016) $\mathrm{R}^{2}$ untuk mengukur proporsi (bagian) atau persentase total variasi dalam $\mathrm{Y}$ yang dapat dijelaskan oleh $\mathrm{X}$ dalam model regresi. Formula menghitung koefisien determinasi adalah:

$$
\mathrm{R}^{2}=(\mathrm{ESS} / \mathrm{TSS})=1-\left(\Sigma e i^{2} / \sum y i^{2}\right)
$$

Kelemahan mendasar dengan menggunakan koefisien determinasi $\left(\mathrm{R}^{2}\right)$ adalah bias terhadap jumlah variabel independen yang dimasukkan ke dalam model. Untuk mengatasi kelemahan tersebut maka dapat digunakan $\mathrm{R}^{2}$ adjusted. Secara matematis, rumus $\mathrm{R}^{2}$ adjusted adalah sebagai berikut:

Adjusted $R^{2}=1-\left(1-\mathrm{R}^{2}\right) \frac{(n-1)}{(k-1)}$

Keterangan :

Adjusted $\mathrm{R}^{2}$ : koefisien determinasi yang disesuaikan

$\mathrm{k}$ : jumlah variabel tidak termasuk intercep

$\mathrm{n}$ : jumlah sampel

\subsection{Pengujian Hipotesis uji F dan uji t}

\subsubsection{Uji F}

Uji F yang dikenal dengan uji serentak atau uji model/ uji anova, dilakukan untuk melihat bagaimanakah pengaruh semua variabel bebasnya secara bersama-sama terhadap variabel terikatnya. Menurut Gujarati (2004) dalam Asni (2016) dirumuskan sebagai berikut:

$\mathrm{F}$ hit $=\frac{\mathrm{ESS} /(\mathrm{k}-1)}{\operatorname{RSS} /(\mathrm{n}-\mathrm{k})}$

$\mathrm{F}$ tabel $\{(\mathrm{k}-1):(\mathrm{n}-\mathrm{k}) ; \alpha\}$

Keterangan :

$\mathrm{k}$ : jumlah variabel tidak termasuk intercept

$\mathrm{n}$ : jumlah sampel

ESS : explained sum of square (jumlah kuadrat dapat dijelaskan)

RSS : residual sum of square (residual jumlah kuadrat tidak dapat dijelaskan.

$\alpha$ : tingkat signifikansi atau kesalahan tertentu

2.4.2. Uji t

Uji t yang dikenal dengan uji parsial yaitu, untuk mengetahui bagaimana masing-masing variabel bebasnya secara sendiri-sendiri terhadap variabel terikat-nya. Menurut Gujarati (2004) dalam Asni (2016) dirumuskan sebagai berikut: 
thit $=\frac{\beta \mathrm{i}}{\operatorname{Se} \beta \mathrm{i}}$

di mana:

$\beta \mathrm{i}$ : koefisien regresi ke-i

Se $\beta i$ : kesalahan standar koefisien regresi ke-i

\section{HASIL DAN PEMBAHASAN}

\subsection{Hubungan Faktor-Faktor Produksi dengan Produksi Usahatani Kopi Arabika}

Berdasarkan hasil analisis, maka faktor produksi yang memiliki hubungan dengan produksi usahatani kopi arabika di Kabupaten Manggarai Timur adalah:

Tabel 1. Analisis Korelasi Faktor-Faktor Produksi dengan Produksi Usahatani Kopi Arabika

\begin{tabular}{lcc}
\hline \multicolumn{1}{c}{ Variabel } & Koefisien Korelasi & Sig. (2-tailed) \\
\hline Pupuk (X1) & $0,439^{* * * *}$ & 0,000 \\
Bibit (X2) & $0,888^{* *}$ & 0,000 \\
Tingkat Pendidikan (X3) & 0,092 & 0,408 \\
Tenaga Kerja (X4) & $0,436^{* * *}$ & 0,000 \\
Luas Lahan (X5) & $0,937^{* *}$ & 0,000 \\
Tanggungan Keluarga (X6) & $0,216^{* *}$ & 0,049 \\
Pengalaman Usahatani (X7) & $-0,177$ & 0,109 \\
Umur Petani (X8) & $-0,208$ & 0,059 \\
\hline Sumber: Hasil Analisis Data Primer & &
\end{tabular}

Keterangan:

**:Korelasi pada Signifikan $1 \%(0,01)$

*: Korelasi pada Signifikan 5\% $(0,05)$

\subsubsection{Pupuk}

Hasil penelitian menunjukkan bahwa variabel pupuk memiliki hubungan dengan produksi secara positif. Nilai signifikan variabel pupuk sebesar 0,000 lebih lebih kecil dari nilai signifikansi sebesar 0,01 yang berarti variabel pupuk memiliki hubungan dengan produksi. Hasil ini sejalan dengan penelitian yang dilakukan oleh Sariani (2017), bahwa pupuk memiliki hubungan dengan produksi.

\subsubsection{Bibit}

Hasil penelitian menunjukkan bahwa variabel bibit memiliki hubungan dengan produksi secara positif. Nilai signifikan variabel bibit sebesar 0,000 lebih kecil dari nilai signifikansi sebesar 0,01 yang berarti variabel bibit memiliki hubungan dengan produksi. Hasil ini sejalan dengan penelitian yang dilakukan oleh Asni (2016), bahwa bibit memiliki hubungan dengan produksi.

\subsubsection{Tenaga Kerja}

Hasil penelitian menunjukkan bahwa variabel tenaga kerja memiliki hubungan dengan produksi secara positif. Nilai signifikan variabel tenaga kerja sebesar 0,000 lebih kecil dari nilai signifikansi sebesar 0,01 yang berarti variabel tenaga kerja memiliki hubungan dengan produksi. Hal ini sejalan dengan penelitian terdahulu yang dilakukan Junaidi (2017), bahwa tenaga kerja memiliki hubungan dengan produksi.

\subsubsection{Luas Lahan}

Hasil penelitian menunjukkan bahwa variabel luas lahan memiliki hubungan dengan produksi secara positif. Nilai signifikan variabel luas lahan sebesar 0,000 lebih kecil dari nilai signifikansi sebesar 0,01 yang berarti variabel luas lahan memiliki hubungan dengan produksi. Hal ini sejalan dengan penelitian yang dilakukan Junaidi (2017), bahwa luas lahan memiliki hubungan dengan produksi.

\subsubsection{Tanggungan Keluarga (Jumlah anggota rumah tangga)}

Hasil penelitian menunjukkan bahwa variabel tanggungan keluarga memiliki hubungan dengan produksi secara positif. Nilai signifikan variabel tanggungan keluarga sebesar 0,049 
lebih kecil dari nilai signifikansi sebesar 0,05 yang berarti variabel tanggungan keluarga memiliki hubungan dengan produksi. Hasil ini sejalan dengan penelitian yang dilakukan Asni (2016), bahwa tanggungan keluarga memiliki hubungan dengan produksi. Faktor-faktor produksi yang tidak memiliki hubungan dengan produksi usahatani kopi arabika.

\subsubsection{Tingkat Pendidikan}

Hasil penelitian menunjukkan bahwa variabel tingkat pendidikan tidak memiliki hubungan dengan produksi. Nilai signifikan variabel tingkat pendidikan sebesar 0,408 lebih besar dari nilai signifikansi sebesar 0,05 yang berarti variabel tingkat pendidikan tidak memiliki hubungan dengan produksi. Hasil ini tidak sejalan dengan penelitian yang dilakukan oleh Asni (2016), bahwa tingkat pendidikan memiliki hubungan dengan produksi.

\subsubsection{Pengalaman Usahatani}

Hasil penelitian menunjukkan bahwa variabel pengalaman usahatani tidak memiliki hubungan dengan produksi. Nilai signifikan variabel pengalaman usahatani sebesar 0,109 lebih besar dari nilai signifikansi sebesar 0,05 yang berarti variabel pengalaman usahatani tidak memiliki hubungan dengan produksi. Hasil ini tidak sejalan dengan penelitian terdahulu yang dilakukan oleh Susanti (2018), bahwa pengalaman usahatani memiliki hubungan dengan produksi.

\subsubsection{Umur Petani}

Hasil penelitian menunjukkan bahwa variabel umur petani tidak memiliki hubungan dengan produksi. Nilai signifikan variabel umur petani sebesar 0,059 lebih besar dari nilai signifikansi sebebesar 0,05 yang berarti variabel umur petani tidak memiliki hubungan dengan produksi. Hal ini sejalan dengan penelitian yang dilakukan Susanti (2018), bahwa umur petani tidak memiliki hubungan dengan produksi.

\subsection{Uji Asumsi Klasik}

Berdasarkan uji asumsi klasik yang dilakukan maka data yang dianalisis berdistribusi dengan normal. Selain itu data yang akan dianalisis tidak terjadi gejala multikolinearitas dan gejala heteroskedastisitas.

\subsection{Faktor-Faktor yang Mempengaruhi Produksi Kopi Arabika}

Penelitian ini bertujuan untuk mengetahui faktor-faktor yang mempengaruhi produksi kopi arabika. Adapun untuk mengetahuinya maka peneliti menggunakan delapan variabel bebas yaitu: umur, tingkat pendidikan, tanggungan keluarga, pengalaman usahatani, bibit, pupuk, luas lahan dan tenaga kerja.

Tabel 2. Hasil analisis Faktor-Faktor yang Mempengaruhi Produksi Usahatani Kopi Arabika

\begin{tabular}{|c|c|c|}
\hline Variabel & Koefisien Regresi & Sig. \\
\hline Pupuk (X1) & 0,022 & 0,377 \\
\hline Bibit (X2) & 0,197 & $0,000^{*}$ \\
\hline Tingkat Pendidikan (X3) & $-0,029$ & 0,578 \\
\hline Tenaga Kerja (X4) & $-0,027$ & 0,642 \\
\hline Luas Lahan (X5) & 0,765 & $0,000^{*}$ \\
\hline Tanggungan Keluarga (X6) & 0,168 & $0,000^{*}$ \\
\hline Pengalaman Usahatani (X7) & 0,02 & 0,789 \\
\hline Umur Petani (X8) & $-0,132$ & 0,434 \\
\hline Konstanta & & 1,317 \\
\hline F hitung & & 122,365 \\
\hline Sig F & & 0,000 \\
\hline Ajusted R Square & & 0,922 \\
\hline $\mathrm{N}$ & & 83 \\
\hline
\end{tabular}

Sumber: Hasil Analisis Data Primer

Keterangan:

$*$ = Signifikan $(99 \%)$ 


\subsection{Pengujian Ketepatan Model}

Berdasarkan tabel 2 diatas diketahui nilai dari Adjusted $\mathrm{R}^{2}$ adalah 0,922. Hal ini menunjukan bahwa faktor produksi pupuk, bibit, tingkat pendidikan, tenaga kerja, luas lahan, tanggungan keluarga, pengalaman usahatani dan umur petani secara simultan (bersama-sama) berpengaruh terhadap produksi usahatani kopi arabika sebesar 92,2\%, sedangkan sisanya sebesar 7,2\%, dipengaruhi oleh faktor lain yang tidak dimasukan dalam model analisis antara lain jarak rumah lahan, pestisida, alat, dll.

Berdasarkan Tabel 2 diketahui faktor-faktor yang berpengaruh secara signifikan terhadap produksi adalah faktor bibit, luas lahan dan tanggungan keluarga; sedangkan faktor-faktor yang tidak berpengaruh secara signifikan adalah pupuk, tingkat pendidikan, tenaga kerja, pengalaman usahatani, umur petani. berikut:

Berdasarkan hasil analisi regresi yang dilakukan, maka didapat persamaan regresi yaitu sebagai

$\mathrm{Y}=1,317+0,022 \mathrm{X} 1+0,197 \mathrm{X} 2-0,029 \mathrm{X} 3-0,027 \mathrm{X} 4+0,765 \mathrm{X} 5+0,168 \mathrm{X} 6+0,02 \mathrm{X} 7-0,132 \mathrm{X} 8+\mathrm{e}$

\subsection{Pengujian Hipotesis}

Untuk melakukan uji $\mathrm{F}$ maka dapat dilihat dari nilai $\mathrm{F}$ hitung pada tebel 2 yaitu sebesar 122,365. Karena nilai $\mathrm{F}$ hitung lebih besar dari $\mathrm{F}$ tabel yaitu sebesar 2,06 maka, dapat disimpulkan bahwa variabel independen secara bersama-sama berpengaruh terhadap variabel dependen. Hal ini menunjukan bahwa pupuk, bibit, tingkat pendidikan, tenaga kerja, luas lahan, tanggungan keluarga, pengalaman usahatani dan umur petani secara simultan (bersama-sama) berpengaruh signifikan terhadap produksi usahatani kopi arabika Kabupaten Manggarai Timur.

Untuk mengetahui faktor produksi apa saja yang berpengaruh secara signifikan terhadap produksi usahatani kopi arabika-Kabupaten Manggarai Timur maka dapat dilakukan dengan uji t. Adapun faktor-faktor yang berpengaruh adalah sebagai berikut:

\subsubsection{Bibit}

Hasil penelitian menunjukkan bahwa variabel bibit berpengaruh terhadap produksi usahatani kopi arabika. Hal ini dapat dilihat dari nilai signifikan variabel bibit pada tabel 2 sebesar 0,000 lebih kecil dari nilai signifikansi sebesar 0,05 sehingga variabel bibit berpengaruh terhadap produksi. Hasil ini tidak sejalan dengan penelitian sebelumnya yang dilakukan Asni (2016), bahwa variabel bibit tidak berpengaruh terhadap produksi.

\subsubsection{Luas Lahan}

Hasil penelitian menunjukan bahwa variabel luas lahan berpengaruh terhadap produksi usahatani kopi arabika di Desa Colol. Nilai signifikan variabel luas lahan sebesar 0,000 yang mana nilai ini lebih kecil dari nilai signifikan sebesar 0,05 sehingga, variabel luas lahan berpengaruh terhadap produksi. Nilai koefisien regresi variabel luas lahan adalah 0,765 hal ini berarti maka akan makin besar produksi kopi arabika sebesar-Hasil ini sejalan dengan temuan penelitian oleh Junaidi (2017),

\subsubsection{Tanggungan Keluarga (jumlah anggota rumah tangga)}

Hasil penelitian menunjukkan bahwa variabel tanggungan keluarga berpengaruh terhadap produksi usahatani kopi arabika. Hal ini dapat dilihat dari nilai signifikan variabel tanggungan keluarga pada tabel 2 sebesar 0,000 yang mana lebih kecil dari nilai signifikansi sebesar 0,05 sehingga variabel tanggungan keluarga berpengaruh terhadap produksi.

Hasil ini sejalan dengan penelitian terdahulu yang dilakukan Asni (2016), bahwa variabel tanggungan keluarga berpengaruh terhadap produksi. Faktor yang tidak berpengaruh nyata terhadap produksi usaha-tani kopi arabika adalah:

\subsubsection{Pupuk}

Hasil penelitian menunjukkan bahwa variabel pupuk tidak berpengaruh terhadap produksi usahatani kopi arabika. Hasil ini tidak sejalan dengan penelitian terdahulu yang dilakukan oleh Thamrin (2017), bahwa pupuk berpengaruh terhadap produksi.

\subsubsection{Tingkat Pendidikan}


Hasil penelitian menunjukan bahwa variabel tingkat pendidikan tidak berpengaruh terhadap produksi usahatani kopi arabika. Hal ini dapat dilihat pada tabel 2 yang mana nilai signifikan variabel tingkat pendidikan sebesar 0,578 lebih besar dari nilai signifikansi sebesar 0,05 sehingga variabel tingkat pendidikan tidak berpengaruh terhadap produksi. Hasil ini sejalan dengan penelitian terdahulu yang dilakukan oleh Asni (2016), bahwa variabel tingkat pendidikan tidak berpengaruh terhadap produksi.

\subsubsection{Tenaga Kerja}

Hasil penelitian menunjukan bahwa variabel tenaga kerja tidak berpengaruh terhadap produksi usahatani kopi arabika Usahatani kopi tidak banyak menggunakan tenagak kerja dalam pengelolaan usaha, karena lebih menyerahkan proses pertumbuhan secara alamiah. Hasil ini tidak sejalan dengan penelitian terdahulu yang dilakukan Junaidi (2017), bahwa tenaga kerja berpengaruh terhadap produksi.

\subsubsection{Pengalaman Usahatani}

Hasil penelitian menunjukan bahwa variabel pengalaman usahatani tidak berpengaruh nyata terhadap produksi usahatani kopi arabika. Hasil ini tidak sejalan dengan penelitian yang dilakukan Susanti (2018), bahwa variabel pengalaman usahatani tidak berpengaruh terhadap produksi.

\subsubsection{Umur Petani}

Hasil penelitian menunjukan bahwa variabel umur petani tidak berpengaruh terhadap produksi usahatani kopi arabika Hasil ini sejalan dengan penelitian yang dilakukan Susanti (2018), bahwa umur petani tidak berpengaruh terhadap produksi.

\section{KESIMPULAN}

Temuan penelitian menyimpulkan bahwa hanya faktor pupuk, bibit, tenaga kerja, luas lahan dan tanggungan keluarga, yang memiliki hubungan dengan produksi sedangkan faktor lainnya tidak. Analisis Cobb Douglas menunjukan bahwa faktor bibit, luas lahan dan tanggungan keluarga berpengaruh terhadap produksi usahatani kopi arabika sedangkan faktor pupuk, tingkat pendidikan, tenaga kerja, pengalaman usahatani dan umur petani tidak berpengaruh terhadap produksi.

\section{DAFTAR PUSTAKA}

Arwinni, Nilam Anisyati. 2017. Analisis Faktor-Faktor Yang Mempengaruhi Produksi dan Pendapatan Usahatani Kacang Tanah Di Kecamatan Camba Kabupaten Maros. AGRISOCIONOMICS. ISSN 2580-0566. 2(1): 31-38

Asni, Nur. 2016. Analisis Faktor-Faktor Yang Mempengaruhi Produksi Dan Pendapatan Usahatani Jambu Mete Di Kecamatan Parangloe Kabupaten. AGROMEDIA. Vol 37. No 4

Chai, D. 2017. Menjelajahi Kopi Colol di Flores.http://travel.compas.com/read/2017/02/27/071000727/menjelajahi.kopi.colol.flores/diaks es 26 Januari 2019.

Junaidi, Ahmad. 2017. Analisis Produksi Kopi di Desa Bocek Kecamatan Karang Ploso Kabupaten Malang. Vol 1. Jilid 1. Hal 92-106.

Muhyidin, Amat. 2010. Analisis Efisiensi Penggunaan Faktor - Faktor Produksi Pada Usaha Tani Padi Di Kecamatan Pekalongan Selatan. http://lib.unnes.ac.id/5444/1/7702.pdf diunduh 26 Januari 2019

Rencana Kerja Tahunan Penyuluhan Pertanian Lapangan. 2019. Programa Penyuluh Pertanian WKPP Ulu Wae Dan Colol Kecamatan Poco Ranaka Timur 2019. Dinas Pertanian Manggarai Timur

Sariani. 2017. Faktor-Faktor yang Mempengaruhi Produksi Kopi di Kecamatan Tinggimoncong Kabupaten Gowa. AGROMEDIA. Vol 36. No 2

Susanti, Novi. 2018. Analisis Faktor-Faktor yang Mempengaruhi Produksi Usahatani Kopi Liberika di Kecamatan Betara Kabupaten Tanjung Jabung Barat. Jurnal

Thamrin, Syahruni. 2017. Faktor-Faktor Yang Mempengaruhi Produksi Usahatani Kopi Arabika Di Kabupaten Enrekang Sulawesi Selatan. AGRIC Vol.26, No. 1 \& No.2 